\title{
Reism, Concretism and Schopenhauer Diagrams
}

Jens Lemanski

University of Hagen

Universitätsstr. 33

58084 Hagen, Germany

e-mail: jens.lemanski@fernuni-hagen.de

\section{Michat Dobrzański}

University of Warsaw

Krakowskie Przedmieście 3 Street

00-927 Warsaw, Poland

e-mail: michaldobrzanski@uw.edu.pl

\begin{abstract}
:
Reism or concretism are the labels for a position in ontology and semantics that is represented by various philosophers. As Kazimierz Ajdukiewicz and Jan Woleński have shown, there are two dimensions with which the abstract expression of reism can be made concrete: The ontological dimension of reism says that only things exist; the semantic dimension of reism says that all concepts must be reduced to concrete terms in order to be meaningful. In this paper we argue for the following two theses: (1) Arthur Schopenhauer has advocated a reistic philosophy of language which says that all concepts must ultimately be based on concrete intuition in order to be meaningful. (2) In his semantics, Schopenhauer developed a theory of logic diagrams that can be interpreted by modern means in order to concretize the abstract position of reism. Thus we are not only enhancing Jan Woleński's list of well-known reists, but we are also adding a diagrammatic dimension to concretism, represented by Schopenhauer.

Keywords: Semantics, Reism, Reification, Abstraction, Philosophy of Language, Logic Diagrams, Jan Woleński.
\end{abstract}

\section{Introduction}

In his article published in The Stanford Encyclopedia of Philosophy on the doctrine of reism, Jan Woleński remarks that it has been anticipated by a number of philosophers from antiquity to modernity. The list includes names such as Thomas Hobbes, Gottfried Wilhelm Leibniz, and Franz 
Brentano, and eventually points at the Polish philosopher Tadeusz Kotarbiński as the one who has presented the "most developed version" of the doctrine [31]. Kazimierz Ajdukiewicz and Woleński concretize the abstract concept of reism by dividing it into an ontological (only things are real) and a semantic dimension (concepts must be reduced to things) [1], [31]. In this paper, we argue (1) that the above-given list should be enhanced by the name of the philosopher Arthur Schopenhauer, who was born in Danzig in 1788 and died in Frankfurt in 1860, and who is for example known for having influenced Wittgenstein [18], [7]. Moreover, we argue not only for reism in Schopenhauer's work but also for the fact (2) that in his Berlin Lectures of the 1820s Schopenhauer has developed a diagrammatic method of concretization.

Argument (1) may seem quite unexpected, given the fact that Schopenhauer is known as a thinker who holds that the whole world is a manifestation of a metaphysical and irrational will [30, p. 34] - a stance that seems to be nowhere less than at complete odds with e.g. Kotabiński's reist program. To prove this not fully adequate, we will focus in Section 2 on Schopenhauer's methodology and offer a reading of it which gives strong foundations for viewing him as a reist. In this section, we will also reconstruct the most important elements of his philosophy of language of his Berlin Lectures as, until recently, they have not drawn much attention among scholars.

Argument (2) is addressed in Section 3. Here, we will develop a diagrammatic method that Schopenhauer used in his Berlin Lectures to illustrate his reistic doctrines. For Schopenhauer, logic diagrams are the best way to concretise what can normally only be expressed in abstract terms. Therefore, we argue that they can show another, namely diagrammatic dimension to understand the position of reism or concretism. These diagrams have already been introduced in [8] as a general tool for philosophy of language. Although the diagrammatic method has certain similarities to the diagram systems of e.g. Leonhard Euler, Immanuel Kant, and even John Venn, we use the term "Schopenhauer diagrams" to avoid further clarifying the relationship to already known logic diagrams.

\section{Schopenhauer's Reist Philosophy of Language}

In this section, we will first give an introduction to Schopenhauer's philosophy of language (2.1), then present his theory of concepts (2.2), and finally argue that Schopenhauer's theory can be called reistic (2.3). In this presentation $(2.1-2.2)$ and argumentation $(2.3)$, we refer mainly to the writings from Schopenhauer's Berlin period (1818 - 1830) and especially to his Berlin Lectures.

\subsection{Introduction to Schopenhauer's Philosophy of Language}

\section{\$1 State of Research}

Despite the claim of Jan Garewicz, the Polish translator of, among others, The World as Will and Representation (WWR) that Arthur Schopenhauer's philosophy "has found a strong resonance in the period of scientism and positivism" [10, p. 32], the German philosopher's work on philosophy of language and logic seems to remain almost unknown to the researchers currently concerned with these topics. This might be somehow connected with the fact that it is in the manuscripts for his Berlin Lectures [23], [24], written in the 1820s, that he dedicates his attention to these issues in the most systematic and profound way. The lectures were until recently ${ }^{1}$ only available in an edition published over 100 years ago, during the ending of a period which might be considered the peak of interest for his philosophy ${ }^{2}$ [3, p. 13 f.]. However, it is not that Schopenhauer does not work on these topics in his other works. In fact, the topics of language and concepts appear in his writings throughout his career, starting from his dissertation (1813) until his final work Parerga and Paralipomena (1851), and seem to constitute an object of his reoccurring philosophical interest which plays an important role for his philosophical system [6, pp. 11-12]. 


\section{\$2 Hierarchies of Language}

In a recent paper, Matthias Koßler argued that Schopenhauer's theory of language cannot be simply reduced to a nominalist, instrumental theory, in which language is treated as a tool for describing empirical objects. However, Koßler admits at the end of his paper that "[n]evertheless Schopenhauer talks about language as a tool [...]" and adds: "He [sc. Schopenhauer] does not reject these aspects of language but places them into a hierarchic order of different uses of language" [15, p. 23]. Without further discussion on whether the instrumental theory of language is the core or just one of several uses of language distinguished by Schopenhauer, it certainly is present in his analysis of language and, significantly for our purpose, it provides a framework which seems to concur with reism ${ }^{3}$.

\section{\$3 Language within Schopenhauer's System}

As the titles of his main work (The World as Will and Representation $=W W R$ ) and the more detailed Berlin Lectures (The Doctrine of the Essence of the World and the Human Spirit) suggest, Schopenhauer assumes that there are only two ways of knowing the world that can be attributed to humans - as representation and as will [25, p. 129], [24, p. 41]. Whereas the parts of his writings in which he discusses the world as will can be, broadly speaking, interpreted as the presentation of his metaphysics, the examination of the world as representation contains elements of his epistemology and methodology. Not surprisingly, Schopenhauer in both works quite early in the presentation of his system already discusses the problem of language and specifically the possibilities of application of concepts for the description of intuitive and mental facts. This discussion can be found in the rather short paragraph 9 of the first volume of WWR (about 10 pages long) and is then significantly enhanced in the notes for Schopenhauer's Berlin Lectures, which encompass more than 100 pages on language and logic.

\section{\$4 Idealism and Empiricism}

The starting point for the construction of Schopenhauer's system seems quite paradoxical. On the one hand, he assumes the Kantian, idealistic view that the "being of things is identical with their cognition" [Das Seyn der Dinge ist identisch mit ihrem Erkanntwerden] [23, p. 113], which he expresses in his claim that all the world is our representation (i.e. the world that we perceive is not the thing-in-itself). On the other hand, Schopenhauer sees the framework of the phenomenal world with its a priori forms of cognition as somehow the natural way of knowing the world ${ }^{4}$ and the only possible foundation for any further philosophical and metaphysical investigations. He opposes any possibility of deducing the truth about the world from reason alone and instead makes the claim that any metaphysics should be founded upon the immanent experience of the subject or even ,empirical sources of knowledge" [23, p. 152], cf. also [14, p. 363]. Thus, Schopenhauer simultaneously assumes (1) the idealist stance that empirical reality is a creation of the subject's cognition and (2) the empiricist distinction of empirical sources and the subject's knowledge. This is possible because he treats the empiricist dualism as the starting point for the construction of a philosophical system, which eventually is monist.

\section{\$5 Ontological and Epistemological Interpretation}

Consequently, the distinction of empirical sources and the subject's knowledge should not be interpreted ontologically, but epistemologically. Schopenhauer does not claim that what is empirical is ultimately real. He only claims that we experience the subject-dependent phenomenal world as having two dimensions, namely intuitive objects and abstract thoughts, and this is the outlook we need to assume as the starting point for philosophical reflection, as from it we get out data for the 
investigation of the world. We need to do so, even if we are philosophically aware of the idealistic character of human cognition.

\subsection{Schopenhauer's Theory of Concepts}

\section{§6 Two Classes of Phenomena}

According to $\S 5$, philosophical reflection sets off with considering the world as representation or a collection of representations (phenomena). These phenomena can be grouped into two classes: (1) intuitive and (2) abstract phenomena. The character of this classification is epistemological, as the reason for it is provided by the different modes of cognition of both classes of representation: (1) intuitive representations are recognized by understanding [Verstand] [23, p. 207], (2) the abstract ones by reason [Vernunft] alone [23, p. 242]. "All our representations", Schopenhauer says, "can generally be divided into visual [anschauliche] and merely thought-like [gedachte], intuitive [intuitiv] and abstract, into images and concepts" [23, p. 118]. As can be seen, this distinction is also equated with the differentiation of phenomena into "images" (which can be "seen") and significantly! - "concepts" (which can be "thought of"). Obviously, this must lead Schopenhauer to provide a solution to such questions as the characteristics of these two classes and their mutual relation.

\section{\$7 Intuitions}

From a systematic point of view, intuitive phenomena are contrary to abstract phenomena. That is, if something is an intuitive phenomenon, it cannot also be an abstract phenomenon and vice versa. From a historical point of view, Schopenhauer dissociates from the theories of mere sensory data of ancient and modern rationalists and empiricists and adopts a reduced Kantian theory of intuition: the intuitive phenomena provide the material data which we can then express in terms of concepts. However, the reception of this data is conditioned by the form of space, time, and causality [23, p. 57, cf. also pp. 146, 172], which allows us to experience, i.e. to absorb sensory data. Therefore, space, time, and causality are a priori valid and they generate the hic et nunc of intuitive representation. In the end, it seems plausible to assume that Schopenhauer understands intuitive representations as reality [Wirklichkeit] [23, p. 207] which is empirical and gives immediate, direct knowledge. However, we need not forget that this dualism between intuitive and abstract phenomena is only epistemological, but not ontological.

\section{$\$ 8$ Concepts}

Concepts, the second class of phenomena, are characterized as "a very peculiar class of representations that exist alone in the human mind" and which are "toto genere different" from intuitive representations. This difference is expressed above all in the fact that concepts can only be thought of abstractly, but not observed in intuitive representation [23, p. 242]. In other words: concepts are not empirical, intuitive objects, but they are experienced by the subject as something like - using modern terminology - mental states. Furthermore, Schopenhauer holds that "every concept as a general, not a specific, representation has what is called a sphere, a circumference", which refers to a set of objects (both other concepts as well as real objects, see below) that can be conceived by it [23, p. 257].

\section{$\$ 9$ Abstraction and Concept}

How, then, are concepts made? Reason produces concepts by abstracting from the many properties of objects that are given in intuitive representation: The concept therefore contains less than the [intuitive, JL\&MD] representation itself"; it is created by "seeing away from what is unique in the 
individual [Wegsehn vom Besondern der Individuen]" [23, pp. 249, 252]. Thus, a concept "does not contain everything" that is given or contained in its intuitive basis. Because of this "innumerable intuitive objects" can be thought of with the help of a concept [23, p. 249]. On the basis of an intuitive representation an abstract, mental reconstruction of it can be formed, which is generally applicable to many other objects in intuitive representation. This generalization, which consists of the liberation from the hic et nunc of intuitive representation (§7), thus enables the mental grasp of abstract, past and future facts, and these in turn can become human motives for action.

\section{$\$ 10$ Generality of Concepts}

Schopenhauer points out that the general applicability of concepts for intuitive representation is not the result of the process of development of concepts - i.e. abstraction from one or many intuitive objects or concepts $(\$ 9)$ - but it is a result of their substantial nature, i.e. their being merely mental, which is characterized by the absence of temporal-spatial determinations. It is, therefore, possible and even necessary that a concept that has arisen by abstracting from properties of one single intuitively given object can potentially be applied to several objects [23, p. 256]. Schopenhauer says: "a concept is always general, even if there is only one thing that is thought by it; and only a singular intuition that gives it content, is a proof of it" [23, p. $276 \mathrm{f}$.].

\section{$\$ 11$ Classes of Concepts}

Concepts, as abstract representations or thoughts, are also divided by Schopenhauer into two general classes, concreta and abstracta. Concreta are abstracted directly from intuitive representations, and abstracta are formed by abstracting from some characteristics of "concepts or genera [Gattungen]". According to his examples, concreta are for instance red, dog, house, and abstracta: color, relation, friendship. He strongly reiterates that this classification is, strictly speaking, inauthentic or wrong, because all concepts are in fact abstract and only "what is intuitive is actually concrete" [23, p. 252]. By using the (inauthentic) terms concretum and abstractum he seems to refer to the original Latin meaning, where abstrahere stands for "taking away" (cf. Schopenhauer's claim that all concepts are an effect of a "seeing away" above) and concrescere for "growing together". The classes are only helpful in understanding the relation of concepts to the empirical world. Schopenhauer uses an allegory: if we think all concepts that we have as a building, then the ground on which it stands will be intuitive representations, the ground floor will be concreta and the higher floors will be abstracta [23, p. 252]. The more general a concept is, the further away it is from empirical reality.

\section{\$12 Intuition-Concept-Hierarchy}

By reference to the classes of concepts $(\S 11)$, Schopenhauer claims an epistemological hierarchy, in which intuitive objects $(\$ 7)$ precede concepts as a source of knowledge. He also denies any kind of innatism, i.e. the presence of a priori concepts in the human mind: "the whole abstract faculty of reason [sc. the conceptual] is a secondary one, which presupposes intuition" [23, p. 235]. The dependence of concepts on intuitive representations is a consequence of how he understands the process of the development of concepts, namely as "reproduction, repetition, of the archetypal intuitively given world" [23, p. 251]. Consequently, concepts become dependent on intuitive reality as the source of information or data that they contain (\$9). This finds its expression for instance in the following quotation: "the whole world of reflection [...] rests on the intuitive one as its basis of cognition" [23, p. 252]. This is the reason, why Schopenhauer repeatedly refers to concepts as "representations of representations" [23, p. 249]. Concepts have meaning only in relation to empirical reality ${ }^{5}$ and the more abstract a concept is, the less meaning it has. ${ }^{6}$ 


\subsection{Schopenhauer's Reism}

\section{$\$ 13$ Reism}

This leads to the core claims of what could be called Schopenhauer's reism. As has been shown, within his basic idealistic outlook $(\S 4)$ he develops a theory of two types of cognition, intuitive and conceptual (§§6-8), and puts them into an epistemological hierarchy ( 12$)$, as he holds that concepts have meaning only in reference to empirical, intuitive objects, without which they would be nothing. But even more crucially, he also holds that concepts can be understood if and only if they can be referred back to intuitions. For a concept to be distinct and meaningful [deutlich], it must be possible to fill it with empirical content. The "common explanation that the concept is distinct if it can be broken down into its characteristics is not enough" as long as these characteristics cannot be traced back to intuitive representation, i.e. to clear perceptions [23, p. 254 f.]. Schopenhauer concludes: "From our entire inquiry it has become evident to everyone that the origin of all knowledge and the foundation of all science lies in direct knowledge, that is, in intuition. Intuition is the last source of all truth: all abstractions, all concepts, are only substitutes and only for their other use, are they the substance of our knowledge; their truth is always an indirect one: the source of all evidence is intuition. All knowledge, all thinking, which does not eventually lead to some kind of intuition, is empty" [23, p. 539].

\section{\$14 Reist Language Criticism}

For Schopenhauer, we only have meaningful [deutliche] concepts if we are able to replace our abstract concepts with references to intuitive reality. It follows that we should be able to break abstracta down to concreta, so that concreta refer [hindeuten] to empirical reality [cf. 23, p. 254 f.]. This idea is also one of the foundations, if not the most important one, of his repeated criticism of Scholastics and German idealists, whose proponents are criticized for their abundant use of very abstract concepts [32]:

"Especially in philosophy, the danger is great that one rises so high from abstraction to abstraction that the way back to intuitive phenomena [Rückweg zum Anschaulichen] is no longer to be found: then the whole knowledge is empty: one operates with mere concepts that are no longer based on intuition: such knowledge is like paper-money that cannot be cashed anywhere" ${ }^{, 7}[23$, p. 539].

Obviously, Schopenhauer is criticizing here the improper use of language, and the problem, which he refers to, is that these philosophers' terminology does not allow a clear reference to reality ${ }^{8}$ [4]. Putting it into reist terms: such abstract terminology cannot be reistically translated.

\section{\$15 Kotarbinski’s Reism}

The stance that abstract concepts need to be broken down into concreta, which again can be referred back to intuition is strongly reminiscent of what Kotarbiński says about how a reist should proceed: "for every declarative sentence (statement) that includes abstract terms he tries to find an equisignificant statement including no such terms". Also, definitions of abstract and concrete terms are provided: "By abstract terms I mean here all those which are not concrete, and by concrete I mean all, and only those, terms which are names of things" [16, p. 441]. This formulation of the reist program is almost identical to Schopenhauer's language criticism and even uses similar terminology. However, one important difference should be pointed out. In Kotarbiński's reism concreta are "names of things". This seems to at least presume the ontological statement that the world, which we conceptualize in language, consists of things. Indeed, soon after its presentation, Kotarbiński's reism was subject to a debate regarding its interpretation as either (1) the ontological 
claim that "every object is a thing" or (2) a semantic program which states that "every 'name' which is not a name of a thing" should be held "for an apparent name" [1, p. $610 \mathrm{f}$.]. It was also pointed out that ontological reism uses abstract terms for expressing its main theses and in consequence should be disqualified according to its own rules [31]. After this criticism, Kotarbiński himself reformulated his reism into a semantic, normative program to free language from abstract names for clarity [31].

\section{\$16 Between Ontological and Semantic Reism}

If we try to consider Schopenhauer's language criticism according to this classification, it seems obvious that his postulate that we should be able to concretize abstracta and eventually refer concepts to intuitions can be interpreted as a semantic program (2) which formulates criteria how language should be used. It can indeed be understood as something quite similar to Kotarbiński's semantic reism, as a "program with the aim of thorough 'de-hypostatization' of humanities" [or better: philosophy], with the goal of "turning it into a discipline which uses clear, simpler and more comprehensible language, even if less 'sublime' or 'deep"” [33, p. $564 \mathrm{f}$.]. The question of whether Schopenhauer could be interpreted also as an ontological reist is more complex, given his steady claim about the idealistic character of representation (\$4), which from a transcendental point of view denies the existence of things.

\section{\$17 Epistemological Concretism}

For this reason, the distinction into ontological and semantic reism seems not appropriate for analyzing Schopenhauer's reism. In fact, the crucial problem is that whereas in Kotarbiński's reism concreta are "names of things", Schopenhauer understands them as direct abstractions from intuitions $(\S 13)$. It has to be underlined at this point that the original term for intuition which he uses is Anschauungen, which in German strongly connotes visuality, as can be seen in $\S 6$, where abstract concepts are confronted with "images". This reiterates the fact that his understanding of the distinction into intuitions and concepts is epistemological and not ontological ( $\$ 5)$. Thus it seems plausible to leave out the ontological question and interpret his semantic reism from $\S 16$ as an epistemological claim, which could be reformulated as follows: "in order to be meaningful, abstract concepts have to be replaceable with concepts which can be intuited [or better in this context: visualized, 'veranschaulichen']". Or more simply: in order to understand concepts we need to visualize them. This is strongly founded upon Schopenhauer's axiomatic claim that all new knowledge lies in intuition [Anschauung] $(\S 12)$ and that only intuition is truly concrete $(\S 11)$. For this reason, the term "reism" seems inadequate and it is more suitable to refer to Schopenhauer's doctrine as "concretism" - a term, which Kotarbiński used synonymously with "reism". However, it should be specified that this is an epistemological, not an ontological concretism [31].

\section{$\$ 18$ Visualization}

To sum up, with recourse to [23, pp. 251-256], one could define the following claims of Schopenhauer's epistemological concretism: (1) only the objects in intuitive representation are concrete; i.e. language is always abstract and only those terms are called (inauthentic) concreta that directly correspond to concrete intuition (\$11). (2) If concepts are to be meaningful [deutlich], it must be possible to break them down into increasingly concrete concepts $(\S 13)$, so that one can finally use these concrete concepts to indicate or to point to intuitive phenomena [hindeuten]. It follows that in order to make concepts comprehensible, we need a theory of visualization. And indeed, Schopenhauer makes several attempts to provide such theories for different fields. He does so e.g. for mathematics (cf. his visualization of the Pythagorean theorem, which he holds to be selfexplanatory [23, p. 425]) or for poetry [24, p. 317], but it is for the visualization of concepts and 
language that he formulates the most developed theory in the Lectures. This theory is based on diagrams, which we discuss in Section 3.

\section{Schopenhauer Diagrams and Epistemological Concretism}

In this section, we will first give a short introduction to Schopenhauer diagrams (3.1), then develop a so-called level theory for concretism (3.2), with the help of which we can finally provide a tool for Schopenhauer's epistemological concretism, a semantic program in many ways similar to reism, in form of intuitive diagrams (3.3).

\subsection{An Introduction to Schopenhauer Diagrams}

\section{\$19 Schopenhauer's Diagrams}

In his Berlin Lectures, Schopenhauer develops a diagrammatic logic that can be used to illustrate semantic positions, topics, and problems. The diagrams that Schopenhauer uses in his treatises on language, logic, and eristic are for him the most important method of concretizing abstract topics since diagrams intuitively illustrate what can only be formulated by using abstract concepts or signs [19]. For Schopenhauer, even abstract algebraic or conceptual theories of mathematics and logic must always be based on an intuitive representation that has an isomorphism to certain diagrams. Although Schopenhauer explains the function of logic diagrams in more detail [20], [5], he does not give precise rules for their application in philosophy of language. In what follows, we will sketch a theory of Schopenhauer diagrams based on four main principles (CI, PI, CE, PE) with which two diagrams given in Schopenhauer's philosophy of language (Fig. 1 and 2) can be analyzed and further developed.
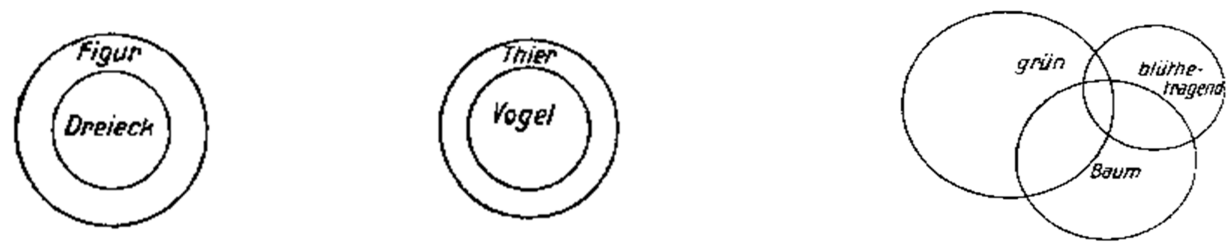

Fig. 1 (PL I, 258): Figur = figure; Dreieck $=$ triangle; Thier $=$ animal; Vogel $=$ bird

Fig. 2 (PL I, 257): grün = green; blüthetragend = flower-bearing; Baum $=$ tree

\section{$\$ 20$ Complete Sphere Inclusion (CI)}

Let us assume that in Fig. 1 we see a diagram that shows at least four terms in the form of four spheres. Two concepts are assigned to a CI, which is shown as a subset $(\subseteq)^{9}$ in the diagram: (CI-1) The sphere that denotes the concept triangle is completely contained within the sphere of the concept figure, i.e. triangle $\subseteq$ figure. (CI-2) The circle denoting the concept bird is completely contained within the sphere of the concept animal, i.e. bird $\subseteq$ animal. In Fig. 2 we find no representation of $\mathrm{CI}$.

\section{\$21 Partial Sphere Inclusion (PI)}

PIs exist when two spheres have an intersection $(\cap)$ in the diagram. In Fig. 1 we find two PIs, since the two larger spheres are partially contained in the smaller spheres: (PI-1) The concept figure is partly contained in the sphere of triangle, i.e. figure $\cap$ triangle. (PI-2) The concept animal is partly contained in the sphere of bird, i.e. animal $\cap$ bird. In Fig. 2 we find even more PIs: (PI-3) The sphere that denotes the concept tree partially intersects the sphere of the concept green, i.e. tree $\cap$ green. (PI-4) Also green and flower-bearing intersect, i.e. green $\cap$ flower-bearing, and 
(PI-5) flower-bearing and tree, i.e. flower-bearing $\cap$ tree. Furthermore, we see in Fig. 2 that PI can also occur with more than two terms, since (PI-6) the sphere of the concepts green, tree and flowerbearing intersect in such a way that there is a common intersection in the middle of the diagram, i.e. green $\cap$ tree $\cap$ flower-bearing.

\section{$\$ 22$ Complete Sphere Exclusion (CE)}

However, Fig. 1 also shows that two of the four spheres with the other two remaining spheres show neither CIs nor PIs $(\Delta)$ : (CE-1) The sphere of the concept figure has neither CIs nor PIs with animal, i.e. figure $\Delta$ animal; (CE-2) Due to (CE-1), (CI-1) and (CI-2) must also apply that triangle and bird possess neither CIs nor PIs, i.e. triangle $\Delta$ bird. From (CE-1) and (CE-2) it is now also evident that one of the larger spheres with one of the smaller spheres has neither CIs nor PIs, i.e. (CE-3) figure $\Delta$ bird and (CE-4) animal $\Delta$ triangle.

\section{\$23 Partial Sphere Exclusion (PE)}

PEs are present when CIs or PIs exist between two conceptual spheres, but a relative complement ( $\backslash$ remains that is not described by CIs or PIs between these two concepts. In Fig. 1 we find two PEs, namely where the inside of the larger sphere is not covered by the smaller one, i.e. (PE-1) figure \triangle and (PE-2) animal \bird. Since PIs were found in Fig. 2, we see here three PEs with two concepts: (PE-3) The sphere denoting the concept tree does partially not intersect the sphere of green, i.e. tree \green. (PE-4) Also green and flower-bearing, i.e. green \flower-bearing, and (PE-5) flower-bearing and tree, i.e. flower-bearing \tree. If one thinks about the union $(U)$ of all three spheres and subtracts (PI-6) from it, the result is one of several possible PE ratios including three concepts, i.e. (PE-6) (green $\cup$ tree $\cup$ flower-bearing) $\backslash$ (green $\cap$ tree $\cap$ flower-bearing).

\section{$\$ 24$ Relations}

Based on $\S \S 2-5$ we can already establish some relations for the individual principles: For CI it is transitive, so that for all spheres $x, y, z$ applies: If CIxy and CIyz, then CIxz. For PI it holds that it is symmetrical so that for all spheres $x, y$ holds: PIxy implies PIyx. Also, CE is symmetric, so for all spheres $x, y$ : CExy implies CEyx. For PE it is not symmetric, because for some spheres $x, y$ is valid (e.g. PE-1, PE-2): If PExy, then not-PEyx.

\section{\$25 Regions and Frames}

Concept development normally starts with only one sphere of a concretum (e.g. bird, animal), but in relation to other spheres they form new ones (e.g. PE-1: animal $\backslash$ bird). This is done by the four principles that form different regions $(\mathrm{R})$ inside and outside a given conceptual sphere. In order to understand this concept formation more precisely, however, it is first necessary to examine the syntax of the respective diagrams with regard to the specific regions. These regions are marked in the diagrams D1 and D2, which structurally correspond to Figs. 1 and 2. To make it clear exactly what belongs to a diagram and what does not, we place a square frame (F) around the diagram. 


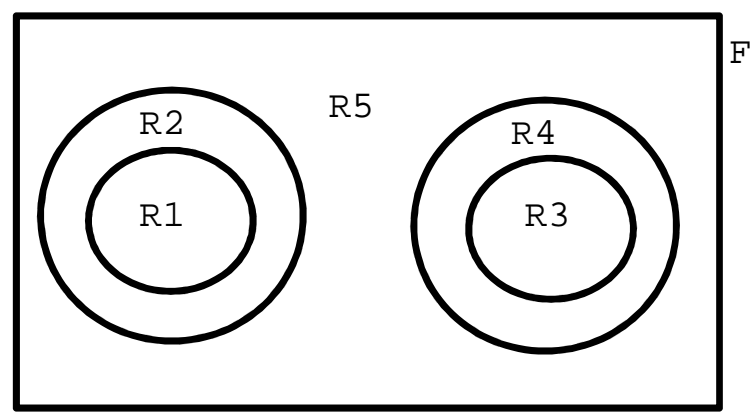

D1

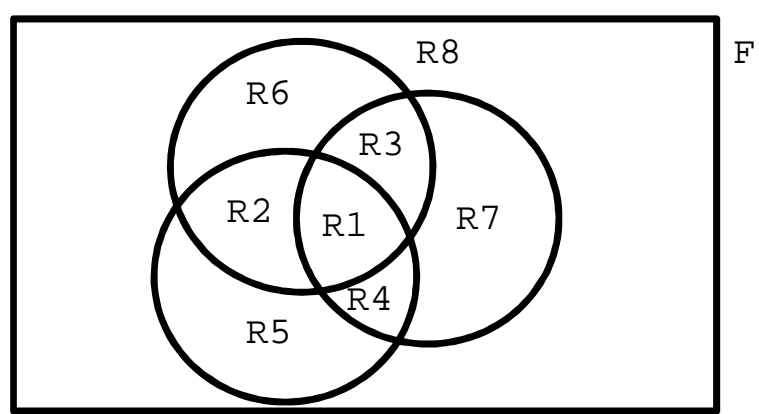

D2

\section{\$26 Semantics of Regions}

If we transfer the semantic meanings that we have gained in Fig. 1 and 2 with the help of the four principles to the syntactic designations of the regions in D1 and D2, we can make the following assignments. For Fig. 1 and D1: $(\mathrm{CI}-1)=\{\mathrm{R} 1\} ;(\mathrm{CI}-2)=\{\mathrm{R} 3\} ;(\mathrm{PI}-1)=\{\mathrm{R} 2\} ;(\mathrm{PI}-2)=\{\mathrm{R} 4\} ;(\mathrm{PE}-$ $1)=\{\mathrm{R} 2\} ;(\mathrm{PE}-2)=\{\mathrm{R} 4\}$. For Fig. 2 and D2 it applies: $(\mathrm{PI}-3)=\{\mathrm{R} 1, \mathrm{R} 2\} ;(\mathrm{PI}-4)=\{\mathrm{R} 1, \mathrm{R} 3\} ;(\mathrm{PI}-$ 5) $=\{\mathrm{R} 1, \mathrm{R} 4\} ;(\mathrm{PI}-6)=\{\mathrm{R} 1\} ;(\mathrm{PE}-3)=\{\mathrm{R} 4, \mathrm{R} 5\} ;(\mathrm{PE}-4)=\{\mathrm{R} 6, \mathrm{R} 2\} ;(\mathrm{PE}-5)=\{\mathrm{R} 3, \mathrm{R} 6\} ;\{\mathrm{R} 5\}$ in D1 must also be present, otherwise (CE-1) and (CE-2) could not be displayed. But if we assume $\{R 5\}$ in D1, we must also consider $\{\mathrm{R} 8\}$ in D2 to be useful, since both are constructed according to the PE principle: (figure $\cup$ animal) $\Delta F=\{\mathrm{R} 5\}$ in $\mathrm{D} 1 ;($ tree $\cup$ green $\cup$ flower-bearing) $\Delta F=\{\mathrm{R} 8\}$ in D2.

\subsection{A Level Theory for Concretism}

\section{$\$ 27$ Abstracta and Concreta}

For Schopenhauer, concepts are not uniform; rather, he distinguishes concepts into different levels, which are classified according to the degree of abstraction or concretion. As described in $\S 11$, the reference to various levels is justified by the allegory of the building: Terms with different degrees of abstraction are assigned to different levels of the building. Although all terms are abstract, they can be divided (inauthentically) into abstracta and concreta. Since we will see below that the division into abstracta and concreta is too imprecise, we add a level degree for concepts $C$ s, in short: $C$-level, which is determined by the number of abstraction steps: $1^{\text {st }}$ level $C, 2^{\text {nd }}$ level $C, n$ level $C$.

\section{\$28 Law of Reciprocity}

Each concept has a certain circumference and content [23, p. 258]. From a modern point of view, one can call the circumference the extension and the content the intension. Extension and intension of a concept $\left(C_{E x t}, C_{I n t}\right)$ stand thereby in an inverse relationship: The larger the extension of a concept, the smaller the intension and vice versa. If, for example, $C_{E x t}$ can be described by a natural number $x$ of a sequence from 0 to $n\left([0, n]:=\left\{x \in \mathbb{N}_{0} \mid 0 \leq x \leq n\right\}\right)$, then $f(x)=n-x$ applies to $C_{\text {Int }}$. This relationship can be called the Law of Reciprocity, which became prominent through Kantian logic [11], [21]. If the number of $C$-level is known, then a suitable quantity can be given for $n$ with the following formula: $n=$ number of C-levels -1 . Let us take the following example: If we set the number of C-levels $=6$, then $n=5$. Furthermore, $C_{E x t}=5$, if $C_{\text {Int }}=0$. If $C_{E x t}=4$, then $C_{\text {Int }}=1$, etc. 


\section{$\$ 29$ Building Scheme}

With the building allegory given in $\S \S 11,27$ we can now set up a scheme (Fig. 3) that illustrates the example of a Law of Reciprocity with $n=5$ given in $\S 28$. Due to the lack of space, the scheme is abbreviated between $2^{\text {nd }}$ level $C$ and $6^{\text {th }}$ level $C$, as indicated by the dotted arrows. Here $3^{\text {rd }}$ level $C\left(C_{E x t}=2\right.$ and $\left.C_{\text {Int }}=3\right), 4^{\text {th }}$ level $C\left(C_{E x t}=3\right.$ and $\left.C_{\text {Int }}=2\right), 5^{\text {th }}$ level $C$ $\left(C_{E x t}=4\right.$ and $\left.C_{\text {Int }}=1\right)$ are missing. At the very bottom is the object that is given in intuitive representation. All $C$ levels are abstractions from intuitive representation. Therefore concepts are also called abstract representations or representations of representations $(\S \S 11,12)$.

\section{\$30 Abstraction and Concretion}

We see in the building scheme (Fig. 3) that between each level processes of abstraction and concretization take place. If one takes up the modern distinction [9], [29] between objectual and conceptual abstraction (or concretion), one can also make a corresponding classification of processes, as can be seen in Fig. 3. Only for conceptual abstraction and concretion applies the Law of Reciprocity (\$28): If conceptual concretion takes place, $C$ loses a degree of extension but gains a degree of intension. In the case of conceptual abstraction, $C$ gains a degree of extension but loses a degree of intension. Note that the sequence from 0 to $n(\$ 28)$ is a degree and does not indicate the actual number of given objects. Since concepts are always general $(\$ 10)$, we can only indicate the degree of the relation between $C_{E x t}$ and $C_{\text {Int }}$, but never the exact number of possible objects designated by $C$.

\section{\$31 Designations of C-levels}

By the building scheme (Fig. 3) it is well recognized that being-abstract and being-concrete are in most cases relative designations: A term has a relative abstraction and concretion if it has a $C$-level above and a term below it. For example, a $2^{\text {nd }}$ level $C$ is more abstract compared to $1^{\text {st }}$ level $C$, but more concrete compared to the $3^{\text {rd }}$ level $C$. In such cases we speak of Abstract-Concrete Concepts or $A C C$ for short. In our example ( $\$ 28$ et seq.) $1^{\text {st }}$ and $5^{\text {th }}$ level $C$ are no ACCs, because they have no $C$-level either below or above. Thus, we can call a $1^{\text {st }}$ level $C$ as a Bottom-Level Concretum or $B L C$ and $5^{\text {th }}$ level $C$ a Top-Level Abstractum or TLA. These designations cannot only be justified diagrammatically but also by using the degrees of $C_{E x t}$ and $C_{I n t}$. For TLA, $C_{E x t}=n$ and $C_{\text {Int }}=0$; for BLC, $C_{E x t}=0$ and $C_{\text {Int }}=n$; and for all ACC, $C_{E x t}$ and $C_{I n t}$ must be $>0$ and $<n$.

\section{$\$ 32$ Concept and Object}

According to $\S 9,30$, a concept is an objectual abstraction of certain objects given in intuitive representation. According to the building scheme (\$26), this definition applies directly to a BLC or $1^{\text {st }}$ level $C$, while all other concepts on a higher $C$-level are abstractions from the lower $C$-levels, i.e. conceptual abstractions ( $\$ 30)$. A concretion of a concept at a higher $C$-level (ACC and TLA) can therefore only be achieved by its reduction to a BLC or $1^{\text {st }}$ level $C$. What this concretion of BLCs might look like, however, is only indicated in Schopenhauer's work: One can say that that objectual 
concretion is made for instance through deictic references ("Hindeuten", §14) accompanying speech acts. ${ }^{10}$ For example, pointing to a certain object when using BLCs such as red, dog, or house ( 111$)$ may be an act of concretion. Anyway, we have represented objectual concretion and abstraction by a simple line in Fig. 3 to illustrate the difference to conceptual concretion or abstraction illustrated by arrows.

\subsection{Concretion of Concretism with Schopenhauer Diagrams}

\section{\$33 A Level Theory for Schopenhauer Diagrams}

But how can the level theory established in Section 3.2 be applied to the Schopenhauer diagrams outlined in Section 3.1? A key to this attempt of making concretism more concrete with the help of a diagrammatic dimension is to focus on the etymological meaning of abstraction and concretion (§11) and its isomorphism with the four principles of Schopenhauer diagrams, i.e. PI, CI, PE, CE (§§ 20-23). In the following, we assume that the I-principles PI and CI correspond to concretion, but the E-principles PE and CE to abstraction. This can be seen in the design of Schopenhauer diagrams since in the case of I-principles spheres grow together (concrescere), whereas in the case of E-principles they are subtracted from each other (abstrahere).

\section{$\$ 34$ Definitions}

We now use the Law of Reciprocity $(\S \S 12,28)$ and say: The more a region $(\S \S 25-26)$ is restricted by I-principles $(\cap, \subseteq)$, the higher is the degree of intension $\left(C_{I n t}\right)$ and the more concrete is the concept. But the more a region is defined by E-principles $(\Delta, \backslash)$, the higher the degree of extension $\left(C_{E x t}\right)$ and the more abstract the concept. We further define that the $\mathrm{C}$-principles have a higher concretion (CI) or abstraction (CE) than the P-principles (PI, PC), if the concepts determined by them are related in one diagram.

\section{\$35 First Example: D1}

In D1, according to $\$ 26$, we find five regions that can be described by all four principles. By referring to $\$ 22$, we see that the regions $\{\mathrm{R} 1\},\{\mathrm{R} 2\},\{\mathrm{R} 3\}$, and $\{\mathrm{R} 4\}$ are in a balanced $\mathrm{CE}$ ratio: Each of these four regions is completely excluded from two others. Thus, for $\{R 1\},\{R 2\},\{R 3\}$ and $\{\mathrm{R} 4\}$, the level degree cannot be determined by CE. According to $\$ 26$, this does not apply to $\{\mathrm{R} 5\}$ : Since $\{\mathrm{R} 5\}=($ figure $\mathrm{U}$ animal) $\Delta F$ and since triangle $\subseteq$ figure $(\mathrm{CI}-1)$ and bird $\subseteq$ animal (CI-2), according to the transitivity-relation of CI (\$24) it applies that $\{\mathrm{R} 5\}=($ triangle $\cup$ bird $) \Delta F$. Thus $\{R 5\}$ is completely excluded from all other conceptual spheres. $\{R 1\}$ and $\{R 3\}$ must be considered as $1^{\text {st }}$ level $C$ or BLC according to the definitions given in $\$ 34$ since they are the only conceptual spheres to which CI principles can be applied (see CI-1 and CI-2 above). For $\{$ R2 $\}$ and $\{$ R4 $\}$, they partly exclude and partly include terms, i.e. $(\mathrm{PI}-1)=\{\mathrm{R} 2\} ;(\mathrm{PI}-2)=\{\mathrm{R} 4\} ;(\mathrm{PE}-1)=\{\mathrm{R} 2\} ;(\mathrm{PE}-2)=$ $\{\mathrm{R} 4\}(\S 23)$.

\section{\$36 Evaluation of D1}

Let us summarize the results of $\S 35$. For $\{R 5\}$ is completely excluded from all other conceptual spheres, $\{\mathrm{R} 2\}$ and $\{\mathrm{R} 4\}$ are partially included, partially excluded, but $\{\mathrm{R} 1\}$ and $\{\mathrm{R} 3\}$ are completely included, then applies: $\{\mathrm{R} 5\}=\mathrm{TLA}\left(3^{\text {rd }}\right.$ level $\left.C\right),\{\mathrm{R} 2\}$ and $\{\mathrm{R} 4\}=\mathrm{ACCs}\left(2^{\text {nd }}\right.$ level $\left.C\right)$, $\{\mathrm{R} 1\}$ and $\{\mathrm{R} 3\}=\mathrm{BLCs}\left(I^{\text {st }}\right.$ level $\left.C\right)$. So since D1 denotes $3 C$-levels, it makes sense to set $n=2$ (§25) and determine that for $\{\mathrm{R} 5\} C_{E x t}=2$ and $C_{I n t}=0,\{\mathrm{R} 2\}$ as well as $\{\mathrm{R} 4\} C_{E x t}=1$ and $C_{\text {Int }}=1$, and $\{\mathrm{R} 1\}$ as well as $\{\mathrm{R} 3\} C_{E x t}=0$ and $C_{\text {Int }}=2$ applies. 


\section{\$37 Second Example: D2}

According to $\$ 26$, we find eight regions in D2 that can be described by three principles, i.e. PI, PE, and CE. Furthermore, $\$ 26$ says that the only $\mathrm{CE}$ region is $\{\mathrm{R} 8\}$, which is excluded from all other regions, i.e. (tree $U$ green $U$ flower-bearing) $\Delta F$. The regions $\{\mathrm{R} 5\},\{\mathrm{R} 6\},\{\mathrm{R} 7\}$ are each formed by two PE and one PI, e.g. $\{\mathrm{R} 6\}=($ green $\backslash$ tree $) \cap($ green $\backslash$ flower-bearing $)$. The regions $\{\mathrm{R} 2\}$, $\{\mathrm{R} 3\}$ and $\{\mathrm{R} 4\}$ are each formed by one PI and one PE, e.g. $\{\mathrm{R} 2\}=($ green $\cap$ tree $) \backslash$ flower-bearing. $\{\mathrm{R} 1\}$, however, is constructed without E-principles, only by PI, e.g. green $\cap$ tree $\cap$ flower-bearing.

\section{\$38 Evaluation of D2}

Let us summarize the results of $\S 37$. For $\{R 8\}$ is completely excluded from all other spheres of concepts, $\{R 5\},\{R 6\}$ and $\{R 7\}$ are partly included, partly excluded, but $\{R 1\}$ is partly included by all spheres, then applies: $\{\mathrm{R} 8\}=\mathrm{TLA}\left(4^{\text {th }}\right.$ level $\left.C\right),\{\mathrm{R} 5\},\{\mathrm{R} 6\}$ and $\{\mathrm{R} 7\}=\mathrm{ACC}\left(3^{\text {rd }}\right.$ level $\left.C\right)$, $\{\mathrm{R} 2\},\{\mathrm{R} 3\}$ and $\{\mathrm{R} 4\}=\mathrm{ACC}\left(2^{\text {nd }}\right.$ level $\left.C\right)$ and $\{\mathrm{R} 1\}=\mathrm{BLC}\left(1^{\text {st }}\right.$ level $\left.C\right)$. So since D2 denotes $4 C$ levels, it makes sense to set $n=3(\S 28)$ and determine that for $\{\mathrm{R} 8\} C_{E x t}=3$ and $C_{\text {Int }}=0$, for $\{\mathrm{R} 5\},\{\mathrm{R} 6\}$ and $\{\mathrm{R} 7\} C_{E x t}=2$ and $C_{\text {Int }}=1$, for $\{\mathrm{R} 2\},\{\mathrm{R} 3\}$ and $\{\mathrm{R} 4\} C_{E x t}=1$ and $C_{\text {Int }}=2$ and for $\{\mathrm{R} 1\} C_{E x t}=0$ and $C_{\text {Int }}=3$ applies.

\section{$\$ 39$ Concretization}

According to $\S 13$, there must be a way back to intuitive phenomena in D1 and D2 if concepts are meaningful [deutlich]. In D1 this means a way back to the two BLCs, either $\{\mathrm{R} 1\}$ or $\{\mathrm{R} 3\}$. In D2 a reduction to $\{\mathrm{R} 1\}$ is required. For $\{\mathrm{R} 1\}$ in $\mathrm{D} 1$, for example, we can say that it is a BLC to which not only the concept figure but also triangle applies. In $\{\mathrm{R} 1\}$ in $\mathrm{D} 2$ we can say that the BLC designates an object that can be described with the expressions green, tree, and flower-bearing. All terms or regions in D1 and D2 which are connected with at least one BLC by an I-principle can be traced back.

\section{$\S 40$ Top-Level Abstracta}

However, TLAs cannot be traced back to BLCs as they are associated with all other terms by the CE-principle. TLAs are therefore characterized by the fact that they are negations of all other terms that are marked in a diagram. From $\{$ R8 $\}$ in D2, for example, we know that it denotes all objects that are not green, not a tree, and not flower-bearing. The amount of objects that it denotes is immeasurable, especially when compared to the objects that are trees, or that are trees and bear flowers, etc. But other than non-tree, non-green and non-flower-bearing, we know nothing of $\{\mathrm{R} 8\}$ in D2. For Schopenhauer, these TLA are not meaningful [deutlich], since there are no positive characteristics. Its extension is very high, but its intension is completely low. Because of the only negative relation to all other concepts in the diagram, a TLA can therefore not be traced back to a concretum, BLC or intuitive representation. According to the reistic criterion (§14) TLAs are therefore only confused [verworren], [23, p. 255] or meaningless words.

\section{Summary and Outlook}

In Section 2, we have presented Schopenhauer's philosophy of language and in particular his theory of concepts as given in the Berlin Lectures. It has been shown that Schopenhauer's theory of concepts can be described as reistic in the widest sense: Without intuitive representations, there would be no abstract representations, so all meaningful abstracta must be reduced to concreta, which indicate to intuitive representations. Reism itself, however, is a concept that remains abstract 
if it is not concretized, as e.g. Jan Woleński does, by pointing out an ontological and a semantic dimension. For Schopenhauer's theory, however, the distinction into ontological and semantic reism seems not appropriate. Rather, it seems to make sense to call his approach epistemic concretism due to the role of concreta and their relationship to concrete representation. 'Concretism', however, is a term, which Kotarbiński used synonymously with 'reism' therefore the choice of words to describe Schopenhauer's theory plays only a minor role. Much more important is that Schopenhauer introduces a further dimension that helps to understand his reistic or concretistic philosophy of language: Schopenhauer uses diagrams to concretize the degrees of abstraction and concretion of concepts and their relationship to the intuitive representation. We have introduced and discussed this diagrammatic dimension of his philosophy of language in Section 3.

However, research on Schopenhauer's philosophy of language and Schopenhauer diagrams is still in its infancy: As already indicated in $\S \S 15$ et seq., for example, we have not yet been able to elaborate on all dimensions involved in Schopenhauer's reism. A more precise attempt at clarification, which we cannot undertake in this paper, would have to discuss, for example, the role of phantasm as a possible reference point of concreta (\$32), but also take into account Schopenhauer's idealistic-transcendental philosophical position with regard to intuitive phenomena. Furthermore, we have reduced Schopenhauer's philosophy of language here to an instrumental theory (\$2). We have also ignored certain contextualist approaches in Schopenhauer's Berlin Lectures.

However, in connection with Schopenhauer's concretism, there are many more historical and systematic questions for future research: Largely unexplained is Schopenhauer's influence on the philosophers and logicians of the early 20th century mentioned in $\S 1$. Furthermore, it can be assumed that Schopenhauer's philosophy of language could be made clearer in a critical comparison with other prominent reists such as Brentano or Kotarbiński. Furthermore, the question remains open whether Schopenhauer's criterion of reist language philosophy also does justice to the controversial concepts of his own theory, e.g. the will, Platonic idea, etc.

Finally, research on Schopenhauer's logic diagrams is also in its infancy: Since Schopenhauer formulated principles of diagram use mainly for the theory of judgement, but not for the philosophy of language, other further interpretations, developments, and applications of his diagrams are conceivable. Of course, the results presented here should also be applied to more complex diagrams that have more than four spheres and where all principles are involved. Furthermore, the question arises as to the relationship of Schopenhauer diagrams to historical ones, e.g. Euler, Kant, Krause, Venn, Peirce diagrams, or to modern systems of diagrams in semantics or logic. This raises the question of which 'observable advantages' Schopenhauer diagrams have and which principles and notations are best suited to describe them [28], [2]. In this paper, however, it was our sole aim to show Schopenhauer's reistic position in his Berlin Lectures and its concretization through Schopenhauer diagrams.

\section{References}

1. Ajdukiewicz, K. ,Elementy teorii poznania' Tadeusza Kotarbińskiego, In T. Kotarbiński, Elementy teori poznania, logiki formalnej $i$ metodologii nauk, Wrocław, Warszawa, Kraków: Zakład Narodowy imienia Ossolińskich, 1961, pp. 607-631.

2. Bellucci, F. Observational Advantages: A Philosophical Discussion, In P. Chapman, G. Stapleton, A. Moktefi, S. Perez-Kriz and F. Bellucci (eds.), Diagrammatic Representation and Inference. Diagrams 2018. Lecture Notes in Computer Science (vol. 10871), Cham: Springer, 2018, pp. 330-335.

3. Beiser, F. C. Weltschmerz. Pessimism in German Philosophy, 1860-1900, Oxford: University Press, 2016.

4. Birnbacher, D. Schopenhauer und die Tradition der Sprachkritik, Schopenhauer-Jahrbuch (99), 2018, 37-56. 
5. Demey, L. From Euler Diagrams in Schopenhauer to Aristotelian Diagrams in Logical Geometry, In J. Lemanski (ed.), Language, Logic, and Mathematics in Schopenhauer, Basel: Birkhäuser (Springer), 2020, pp. 181-206.

6. Dobrzański, M. Begriff und Methode bei Arthur Schopenhauer, Würzburg: Königshausen \& Neumann, 2017.

7. Dobrzański, M. Problems in Reconstructing Schopenhauer's Theory of Meaning: With Reference to His Influence on Wittgenstein, In J. Lemanski. (ed.), Language, Logic, and Mathematics in Schopenhauer, Basel: Birkhäuser (Springer), 2020, pp. 25-45.

8. Dobrzański, M., and J. Lemanski. Schopenhauer Diagrams for Conceptual Analysis, In A.-V. Pietarinen, Diagrammatic Representation and Inference. 11th International Conference, Diagrams 2020 Tallinn, Estonia, August 24-28, 2020, Lecture Notes in Artificial Intelligence (vol. 12169), Cham: Springer, 2020, pp. 281-288.

9. Fine, K. The Limits of Abstraction, Oxford: Clarendon Press, 2002.

10. Garewicz, J. Schopenhauer, Warszawa: Wiedza Powszechna, 1988.

11. Hauswald, R. Umfangslogik und analytisches Urteil bei Kant, Kant-Studien (101), 2010, pp. 283-308.

12. Juhos, B. Inwieweit ist Schopenhauer der Kantischen Ethik gerecht geworden? Wien: Phil. Diss., 1926.

13. Kleszcz, R. Criticism and Rationality in the Lvov-Warsaw School, In D. Kubok (ed.), Thinking Critically: What Does It Mean? The Tradition of Philosophical Criticism and Its Forms in the European History of Ideas, Berlin, Boston: de Gruyter, 2018, pp. 161-172.

14. Koßler, M. Die eine Anschauung - der eine Gedanke. Zur Systemfrage bei Fichte und Schopenhauer, In L. Hühn (ed.), Die Ethik Arthur Schopenhauers im Ausgang vom Deutschen Idealismus (Fichte/Schelling), Würzburg: Ergon, 2006, pp. 349-364.

15. Koßler, M. Language as an 'Indispensable Tool and Organ' of Reason: Intuition, Concept and Word in Schopenhauer, In J. Lemanski (ed.), Language, Logic, and Mathematics in Schopenhauer, Basel: Birkhäuser (Springer), 2020, pp. 15-24.

16. Kotarbiński, T. Reism: Issues and Prospects, Logique et Analyse 11 (44), 1968, pp. 441-458.

17. Kotarbiński, T. Przedmowa, In A. Schopenhauer, Erystyka czyli sztuka prowadzenia sporów, Kraków: Wydawnictwo Literackie, 1973.

18. Lemanski, J. Schopenhauers Gebrauchstheorie der Bedeutung und das Kontextprinzip: Eine Parallele zu Wittgensteins >Philosophischen Untersuchungen<, Schopenhauer Jahrbuch (97), 2016, pp. 171-195.

19. Lemanski, J. Means or End? On the Valuation of Logic Diagrams, Logiko-filosofskie studii (14), 2016, pp. 98-122.

20. Moktefi, A. Schopenhauer's Eulerian diagrams, In J. Lemanski (ed.), Language, Logic, and Mathematics in Schopenhauer, Basel: Birkhäuser (Springer), 2020, pp. 111-128.

21. McLaughlin, P., and O. Schlaudt. Kant's Antinomies of Pure Reason and the 'Hexagon of Predicate Negation', Logica Universalis (14), 2020, pp. 51-67.

22. Schlick, M. Nietzsche und Schopenhauer, In M. Schlick (ed. Iven, M.), Gesamtausgabe: Abteilung II: Nachgelassene Schriften, vol. 5.1, Wien, New York: Springer, 2013.

23. Schopenhauer, A. Philosophische Vorlesungen. Vol. I, In A. Schopenhauer (ed. P. Deussen and F. Mockrauer), Schopenhauers sämtliche Werke. Vol. IX., München: Piper, 1913.

24. Schopenhauer, A. Philosophische Vorlesungen. Vol. II, In A. Schopenhauer (ed. P. Deussen and F. Mockrauer), Schopenhauers sämtliche Werke. Vol. X., München: Piper, 1913.

25. Schopenhauer, A. The World as Will and Representation. Vol. 1., translated and edited by Judith Norman, Alistair Welchman and Christopher Janaway, Cambridge: Cambridge University Press, 2010.

26. Schopenhauer, A. Der handschriftliche Nachlass: Bd. III. Berliner Manuskripte (1818-1830), ed. by A. Hübscher, Frankfurt a.M.: W. Kramer, 1970.

27. Schopenhauer, A. Parerga and Paralipomena. Vol. 2., transl. by A. Del Caro, C. Janaway, Cambridge: Cambridge University Press, 2015. 
28. Stapleton, G., Jamnik, M., and A. Shimojima. What Makes an Effective Representation of Information: A Formal Account of Observational Advantages, Journal of Logic, Language and Information 26 (5), 2017, pp. 143-177.

29. Tennant, N. A General Theory of Abstraction Operators, The Philosophical Quarterly 54 (214), 2004, pp. 105-133.

30. Woleński, J. The History of Epistemology, In I. Niiniluoto, M. Sintonen and J. Wolenski (eds.) Handbook of Epistemology, Dordrecht: Kluwer Academic, 2004, pp. 3-54.

31. Woleński, J. Reism, In E. N. Zalta (ed.), The Stanford Encyclopedia of Philosophy (Summer 2012 Edition), URL: http://plato.stanford.edu/archives/sum2012/entries/reism/ (11.05.2020).

32. Xhignesse, M.-A. Schopenhauer's Perceptive Invective, In J. Lemanski (ed.), Language, Logic, and Mathematics in Schopenhauer, Basel: Birkhäuser (Springer), 2020, pp. 95-109.

33. Zaręba, M. Reizm Tadeusza Kotarbińskiego a prakseologiczna koncepcja sprawstwa, Przegląd Filozoficzny - Nowa Seria 3 (83), 2012, pp. 559-575.

\section{Notes}

1. A slightly modified re-print was published by Volker Spierling in 1984ff. A new edition of the lectures by Daniel Schubbe is currently being published at Felix Meiner Verlag. The publication of the part containing Schopenhauer's considerations on language and logic is currently scheduled for December 2020. An English translation does not yet exist.

2. Beiser points out that the interest in Schopenhauer peaked between the years 1860 and 1914 . Significantly, this is also a period in which the founding texts of modern philosophy of language appear. Whether there is any relation between these two facts, however, needs further examination, even if it has already been pointed out that Schopenhauer's philosophy had an impact on Wittgenstein [18], and there is an obvious reception of Schopenhauer in Logical Positivism (e.g. Béla Juhos wrote his PhD-thesis on Schopenhauer [12] and Moritz Schlick lectures on Schopenhauer [22]) and in the Lvov-Warsaw School (e.g. Schopenhauer was quoted at various texts of Kazimierz Twardowski and Kotarbiński wrote the introduction to the Polish translation of Schopenhauer's Eristic Dialectic [17]).

3. In this respect, Kotarbiński is very precise: "Thus it is obvious that reism, or concretism, is a variation of nominalism" [16, p. 442].

4. In his Lectures he states for example that this is the way of knowing the world by the "philosophically crude" people, who have not yet philosophically reflected upon the world [23, p. 463].

5. In his Berlin period, Schopenhauer found the term "natural education" for this, by which he postulated that empirical experience precede abstract knowledge [26, p. 260; 27, pp. 562-563].

6. For a more detailed explanation of this, encompassing some terminological problems of Schopenhauer's theory, see [7, p. $33 \mathrm{ff}$.]

7. It has to be pointed out here that Kotarbiński uses a very similar allegory of paper-money in reference to abstract concepts and their role in the reist outlook: "Every banknote, cheque, and promissory note must be exchangeable into gold on demand, which does not mean that all payments are made in gold" [16, p. 444].

8. Interestingly enough, the founder of the Lvov-Warsaw School, Kazimierz Twardowski, also formulated such criticism of German Idealism [13, p. 162].

9. Schopenhauer diagrams are not diagrams of set theory, but nevertheless the notation of set theory is suitable for describing Schopenhauer diagrams. In contrast to naïve set theory, however, we normally assign only one principle, and thus one set-theoretical sign, to each relation of two diagrammatic elements. A detailed study of the notation of Schopenhauer diagrams is planned for the future.

10. Schopenhauer assumes that there are also other possibilities, e.g. though phantasms [6, p. 43 ff.]. 